\section{A LegislaçÃo PROCESSUAL TRABALHISTA E O USO DA INTERNET}

Recebimento do artigo: 15/04/2007

Aprovado em: 26/04/2007

\section{Adalberto Martins}

\section{Resumo}

O presente trabalho objetiva uma breve análise das inovações legislativas, que prestigiam o uso das tecnologias da informação no âmbito do direito processual, e que se revelam aplicáveis ao processo do trabalho, com vistas à efetividade dos direitos sociais trabalhistas, em homenagem ao disposto no art. $5^{\circ}$, LXXVIII, da Constituição Federal, acrescentado pela Emenda Constitucional n. 45/2004.

\section{Palavras-chave}

Sociedade da informação. Direito na sociedade da informação. Direito e internet. Processo do trabalho e internet. Celeridade processual. Tecnologias da informação no direito.

\section{Abstract}

The presentpaper aims to present a brief analysis of the legislative innovations, that give prestige to the use of the information technologies in the legal procedural field, which turns out to be applicable to the labor lawsuit, aiming the effectiveness of the social laborite rights, in honor to the determination in the art.5th, LXXVIII, of the Federal Constitution, added by the Constitutional Amendment n. 45/2004.

\section{Key words}

Society of the information. Law of the society of the information. Law and internet. Labor Lawsuit and internet. Procedural Celerity. Information Technology in Law.

OSASCO, ANO 7, N.1, 2007, P. 185-194 


\section{Considerações iniciais}

A sociedade da informação, era da informática, sociedade pós-industrial, sociedade pós-moderna e terceira revolução industrial são expressões distintas que costumam ser usadas para uma síntese do mesmo fenômeno, e que deve ser debitado à globalização. Já não se duvida que as tecnologias da informação, notadamente o uso da internet, provocaram uma revolução nos costumes com reflexos nas relações jurídicas, inclusive naquelas travadas entre países muito distantes do ponto de vista geográfico, aspecto inclusive lembrado pelo primeiro-ministro da Índia, Manmohan Singh, em visita ao Brasil ${ }^{1}$.

As novas tecnologias apresentam reflexos em toda e qualquer relação jurídica, não ficando excluídas as relações jurídicas processuais, que se desenvolvem no âmbito dos órgãos investidos da jurisdição daí nossa breve incursão, e apresentação de visão panorâmica dos reflexos observados no processo do trabalho, e que só foram possíveis porque a Justiça do Trabalho, muito antes das inovações legislativas que têm sido observadas, ocupou-se da própria modernização. Apenas para ficar com o exemplo de São Paulo (TRT-2a Região), o projeto de informatização foi iniciado em meados de 1992, e tornou-se realidade há pouco mais de dez anos.

A modernização referida, em determinado momento, representou a substituição das antigas máquinas de escrever manuais por máquinas elétricas e, posteriormente, pelas eletrônicas mais sofisticadas e que já comportavam alguma memória para a repetição de pequenos textos nas intimações ou nas atas de audiência. Contudo, ainda não se conhece nada que tenha sido mais revolucionário que o uso das tecnologias da informação, que tem por base a internet, e que está para a sociedade da informação (ou sociedade pós-industrial, como preferem alguns estudiosos) assim como o uso da eletricidade está para a sociedade industrial ${ }^{2}$.

A informatização da Justiça do trabalho trouxe inúmeras vantagens para a efetividade da tutela dos direitos sociais trabalhistas, que superam as dificuldades que decorrem da dependência criada em torno das mesmas tecnologias, a exemplo do que ocorreu por ocasião da descoberta da eletricidade, que representou verdadeira revolução nos costumes, e da qual o homem moderno não admite prescindir. Não são poucos os que não se imaginam sem o uso diário do computador e, menos ainda, sem o uso da internet.

\footnotetext{
1 "Nós reconhecemos que a modernidade e a tecnologia tornaram o conceito de distância geográfica irrelevante. A globalização é uma realidade”. Cf. FOLHA DE SÃO PAULO, p. B10, 06 set. 2006, ${ }^{2}$ Cf. CASTELLS, Manuel. A galáxia internet: reflexões sobre internet, negócios e sociedade. Lisboa: Fundação Calouste Gulbenkian, 2004, p. 15.
} 
A Justiça do Trabalho já não conseguiria cumprir a sua função jurisdicional sem o uso regular das tecnologias da informação. Bastam alguns minutos sem o funcionamento do sistema informatizado para percebermos os transtornos causados a advogados, a partes, a funcionários e a juizes, em face de processos não localizados, de guias de depósito e alvarás que não podem ser emitidos, de audiências que não são realizadas e de tantas outras tarefas que se inserem na rotina de uma secretaria de Vara do Trabalho ou de Turma no Tribunal.

Diante dessas considerações, passamos à breve abordagem em torno da penhora on line na Justiça do Trabalho e das recentes inovações do Código de Processo Civil, adotadas no processo do trabalho. Finalmente, faremos algumas considerações sobre a Lei n. 11.419/06 ${ }^{3}$, que disciplina a informatização do processo judicial, no âmbito civil, penal e trabalhista, inclusive de juizados especiais, em qualquer grau de jurisdição.

\section{A penhora on line}

Superada a fase de organização das próprias atividades, com o sistema informatizado em pleno funcionamento, foi possível o desafio da penhora on line no âmbito da Justiça do Trabalho que, no início, nada mais representou senão o aperfeiçoamento da penhora em dinheiro, prevista no Código de Processo Civil (art.655, I), aplicável ao processo do trabalho por expressa determinação do art.882 da CLT, dispositivo legal que teve redação ampliada por força da Lei 11.382, de 06.12.2006 ${ }^{4}$. Trata-se de procedimento que decorre de convênio firmado entre o Tribunal Superior do Trabalho e o Banco Central do Brasil em 05.03.2002, denominado "Convênio de Cooperação Técnico-Institucional", que permite o bloqueio de contas correntes e de aplicações financeiras do executado, mediante acesso ao Sistema Bacen Jud, com vistas a garantir o pagamento da dívida trabalhista (penhora, propriamente dita), ou até mesmo o resultado útil do processo trabalhista em ações cautelares (arresto, por exemplo).

Os argumentos em sentido contrário à penhora on line são facilmente refutados, pois não se trata de medida que se encontrava na dependência de inovação legislativa ${ }^{5}$, tampouco lhe pode ser atribuída a pecha de inconstitucional, já que

\footnotetext{
${ }^{3}$ Trata-se de lei recentemente integrada ao ordenamento jurídico, oriunda do Projeto de Lei da Câmara n. 71/2002, publicada em 20.12.2006, e que já se encontra em plena vigência, eis que superada a vacatio legis de 90 dias determinada em seu artigo 22.

${ }^{4}$ Art.655 do CPC: “A penhora observará, preferencialmente, a seguinte ordem: I - dinheiro, em espécie ou em depósito ou aplicação em instituição financeira;"

${ }^{5}$ Além disso, todas as dúvidas em torno da legalidade da referida modalidade de constrição judicial foram dissipadas pelo art.655-A do CPC, também acrescentado pela Lei n. 11.382/06: "Para possibilitar
} 
não implica, por si só, o desrespeito ao devido processo legal, nem ao sigilo bancário. Trata-se de providência que se mostrou eficaz na efetivação de direitos sociais trabalhistas, reconhecidos em sentença judicial e até mesmo em acordos homologados em juízo, mas não cumpridos pelo reclamado, muitos deles com execução pendente há vários anos, com o executado na certeza de que ficaria impune.

As imperfeições iniciais que decorriam do convênio firmado entre o Banco Central do Brasil e o Tribunal Superior do Trabalho já se encontram perfeitamente superadas. Aqueles que insistem na crítica são exatamente os mesmos que não estão preocupados com a efetividade da tutela jurisdicional, e sim com os próprios e inconfessáveis interesses.

\section{O processo do trabalho e as inovações do Código de Processo Civil}

O processo do trabalho, concebido para viabilizar com celeridade e simplicidade, a solução estatal de conflitos trabalhistas, tanto que sequer foi codificado, se vê às voltas com mais uma avalanche de normas que transformam o direito processual civil, com vistas à efetividade da jurisdição dentro da nova realidade, decorrente de sociedade pós-industrial, dominada pelas tecnologias da informação.

Diante desse cenário, impõe-se indagar sobre a aplicação dos novos dispositivos legais na seara trabalhista, sem perder de vista o fato de que o direito processual comum é fonte subsidiária do direito processual do trabalho, desde que se constate a omissão na legislação trabalhista, e não haja incompatibilidade com as normas processuais que regem o processo laboral (art. 769 da CLT).

A possibilidade de aplicação subsidiária do processo civil, desde que verificadas as duas premissas já mencionadas, desautoriza qualquer ilação de autonomia do direito processual do trabalho, não obstante reconheçamos que possui algumas peculiaridades que emergem da própria desigualdade econômica entre empregado e empregador, os maiores destinatários de suas normas.

O direito processual do trabalho tem como objetivo principal, claro e específico, disciplinar a solução dos conflitos que decorrem das relações de trabalho, segundo a dicção do art.114 da Constituição Federal, com a redação da Emenda Constitucional n.45/2004, por meio da tutela jurisdicional do Estado (Justiça do

\footnotetext{
a penhora de dinheiro em depósito ou aplicação financeira, o juiz, a requerimento do exeqüente, requisitará à autoridade supervisora do sistema bancário, preferencialmente por meio eletrônico, informações sobre a existência de ativos em nome do executado, podendo no mesmo ato determinar sua indisponibilidade, até o valor indicado na execução".
} 
Trabalho). Tudo isto, com observância dos princípios constitucionais que norteiam a referida atividade estatal, sem qualquer inclinação favorável a uma das partes. A aparente proteção que a própria Consolidação das Leis do Trabalho consagra ao trabalhador, mesmo no âmbito do processo do trabalho, nada mais objetiva senão assegurar a igualdade das partes, pois a inferioridade econômica deste último, aliada à inaptidão para produzir as provas necessárias, justifica a superioridade jurídica que decorre, por exemplo, da opção legislativa quanto ao art.844 da CLT e ao entendimento jurisprudencial da súmula 338 do TST.

Passemos, pois, ao estudo das inovações do processo civil que se revelam aplicáveis ao processo do trabalho.

\subsection{A inovação da Lei n. 9.800/99}

O uso das inovações tecnológicas no processo civil foi inaugurado pela Lei n. 9.800, de 26.5.1999, ao facultar a utilização de sistema de transmissão de dados e de imagens, do tipo fac simile ou similar, para a prática de atos processuais que dependam de petição escrita, desde que observado o prazo, e haja a entrega dos originais em juízo, até cinco dias após o seu término. Trata-se de inovação legislativa bem recebida no âmbito da Justiça do Trabalho, inclusive com jurisprudência cristalizada na súmula 387 do TST:

I - A Lei no 9.800/1999 é aplicável somente a recursos interpostos, após o início de sua vigência. (ex-OJ 194 - inserida em 8.11.2000) II - A contagem do qüinqüídio para apresentação dos originais de recurso interposto por intermédio de fac-símile começa a fluir do dia subseqüente ao término do prazo recursal, nos termos do art. $2^{\circ}$ da Lei n ${ }^{\circ} 9.800 / 1999$, e não do dia seguinte à interposição do recurso, se esta se deu antes do termo final do prazo. (ex-OJ 337 - primeira parte - DJ 4.5.2004) III - Não se tratando a juntada dos originais de ato que dependa de notificação, pois a parte, ao interpor o recurso, já tem ciência de seu ônus processual, não se aplica a regra do art.184 do CPC quanto ao dies a quo, podendo coincidir com sábado, domingo ou feriado. (ex-OJ 337 - in fine - DJ 4.5.2004)

A inovação da Lei 9.800/99, que não se destinava exclusivamente à prática de atos processuais por meio de fac-símile, possibilitou ao Tribunal Regional do Trabalho da $2^{\text {a }}$ Região, por meio do Provimento GP no 07/2001, a criação do Sistema de Petição Eletrônica (SIPE), posteriormente substituído pelo Processo Eletrônico Trabalhista (Provimento GP no 05/2002, introduzindo no âmbito da Justiça do Trabalho da $2^{\text {a }}$ Região, o peticionamento e o uso da assinatura eletrônica. Ainda não se trata de processo virtual, pois a petição eletrônica é impressa pelos órgãos da Justiça do Trabalho e juntada aos autos do processo. 
Trata-se de caminho seguido posteriormente pelo Tribunal Superior do Trabalho, ao editar a Instrução Normativa n. 28, aprovada pela Resolução n. 132/2005, publicada no D.J.U. de 7.6.2005, que cria o Sistema Integrado de Protocolização e Fluxo de Documentos Eletrônicos (e-DOC). Assim permite-se que as partes, advogados e peritos, apenas no âmbito da Justiça do Trabalho, utilizem a internet para a prática de atos processuais dependentes de petição escrita, desde que haja o prévio cadastramento da identidade digital adquirida perante qualquer Autoridade Certificadora credenciada pela ICP-Brasil, nos termos da Medida Provisória n. 2.200-2, de 24.8.2001. A iniciativa do Tribunal Superior do Trabalho, sem dúvida nenhuma, motivou a realidade do peticionamento eletrônico nos demais tribunais trabalhistas do país.

\subsection{A inovação da Lei n. 11.280/06}

Dentre as novidades da Lei $11.280 / 06$, a consolidação do peticionamento eletrônico, por meio do parágrafo único acrescentado ao art.154 do Código de Processo Civil, é aquela mais sentida no âmbito do processo do trabalho. Dispõe o art.154, parágrafo único do CPC, que:

Os tribunais, no âmbito da respectiva jurisdição, poderão disciplinar a prática e a comunicação oficial dos atos processuais por meios eletrônicos, atendidos os requisitos de autenticidade, integridade, validade jurídica e interoperabilidade da Infra-Estrutura de Chaves Públicas Brasileira ICP - Brasil ${ }^{6}$.

Em verdade, a prática de atos processuais por meio eletrônico já era possível, tendo em vista a Lei 9.800/99 e o fato de que o caput do art.154 do Código de Processo Civil já consagrava o princípio da instrumentalidade das formas.

Assim, conforme observado no tópico anterior, o peticionamento eletrônico já é uma realidade no TRT-2 ${ }^{\mathrm{a}}$ Região, desde meados de agosto de 2001 (Provimento GP 07/2001, de 10.08.2001, publicado no DOE/SP de 13.08 e 14.08.2001), e até mesmo o Tribunal Superior do Trabalho ocupou-se da questão, por meio da

\footnotetext{
${ }^{6}$ A redação do mencionado dispositivo legal teria sofrido significativa alteração com a Lei n. 11.419/06, que facultava aos tribunais, no âmbito das respectivas jurisdições, disciplinar a prática e a comunicação oficial dos atos processuais por meios eletrônicos, sem o uso obrigatório da ICP-Brasil, e que foi vetado pelo presidente da República. Portanto, permanecem atuais as críticas de Rodrigo da Cunha Lima Freire, para quem “... a vinculação dos atos processuais eletrônicos aos requisitos da ICP-Brasil, exigida pelo novel parágrafo único do art.154 do CPC, pode representar uma verdadeira 'camisa de força' ou mais um obstáculo à prática e à comunicação eletrônica dos atos processuais, tendo em vista que poucos órgãos estão oficialmente habilitados a conferir a certificação de autenticidade, de integridade e de validade jurídica de documentos em forma eletrônica por esse sistema”. (FREIRE, Rodrigo da Cunha Lima. Direito fundamental à tutela jurisdicional efetiva na sociedade informacional. In: PAESANI, Liliana Minardi (coord.). O direito na sociedade da informação. São Paulo: Atlas, 2007, p. 305-306).
} 
Instrução Normativa n. 28/2005. A inovação legislativa reside no fato de que a prática de atos processuais por meio eletrônico não ficará mais restrita a advogados, partes e peritos, mas também abarcará funcionários, juizes e os membros do Ministério Público nas causas em que atuar como fiscal da lei, e para isso a Justiça do Trabalho já está se empenhando na concessão de certificação digital para os magistrados que assim desejarem, e já se tem notícia da primeira decisão monocrática firmada por meio de assinatura digital no Tribunal Regional do Trabalho da $4^{\mathrm{a}}$ Região.

Diante dos expressos termos do parágrafo único do art.154 do CPC, o Tribunal Regional do Trabalho da $2^{\text {a }}$ Região se encarregou de editar o Provimento GP/CR n. 14/2006, que revoga o anterior (Provimento GP 05/2002), e disciplina toda a matéria, também em conformidade com a Instrução Normativa n. 28/2005 do Tribunal Superior do Trabalho, que instituiu o Sistema de Protocolização de Documentos Físicos e Eletrônicos (SisDoc), inclusive com prazo inicial de 90 dias para que os usuários adquirissem a certificação digital que pudesse atender os requisitos de autenticidade, integridade, validade jurídica e interoperabilidade da Infra-Estrutura de Chaves Públicas Brasileira - ICP-Brasil ${ }^{7}$, perante autoridade certificadora prorrogado para 180 dias.

O peticionamento eletrônico traduz-se em faculdade posta à disposição de advogados, procuradores e terceiros que necessitem atuar no processo, e que vem sendo adotado pela grande maioria dos tribunais trabalhistas do país, a exemplo do TRT-15 Região (Campinas/SP - Portaria GP nº2/2002), TRT-4 ${ }^{a}$ Região (Porto Alegre/RS - Provimento no 04/2004) e TRT-17ª Região (Vitória/ES - Ato.TRT.17 ${ }^{a}$ PRESI n³20/2005) mas ainda não contempla a prática e comunicação dos atos processuais por servidores e juízes do trabalho, o que virá em futuro próximo, tendo em vista o teor da Lei n. 11.419/06, oriunda de aprovação do Projeto de Lei da Câmara n. 71/2002, pois a nova realidade é irreversível, já se encontrando aberto o caminho para o processo virtual.

\subsection{O processo do trabalho e a Lei n. 11.341/06}

Nos termos do parágrafo único do art.541 do CPC, com a redação da Lei 11.341, publicada no D.O.U de 8.8.06, as decisões disponíveis em mídia eletrônica, inclusive

\footnotetext{
${ }^{7}$ Entendemos que doravante, a prática de atos processuais por meio eletrônico dependerá de identidade digital fornecida por autoridade certificadora credenciada pela ICP-Brasil, em nada favorecendo o argumento de que a simplicidade do processo do trabalho recomenda tratamento menos rigoroso, pois há a necessidade de se assegurar a autenticidade, integridade e validade jurídica do ato processual, que poderia ser comprometida com a aceitação de outros padrões de comunicação.
} 
na internet, também se destinam à prova de divergência jurisprudencial nos casos de interposição de recurso especial e extraordinário. No processo do trabalho, o recurso de revista (art.896 da CLT) traduz-se em sucedâneo do recurso especial e, diante da omissão dos arts. 896 , alíneas $a$ e $b$, e $\$ 4^{\circ}$,da CLT, que se dedicam ao tratamento da divergência jurisprudencial destinada ao conhecimento do mencionado recurso, não há dificuldades em se admitir a aplicação subsidiária da inovação do Código de Processo Civil, nos termos do art.769 da CLT, haja vista a ausência de incompatibilidade com o processo trabalhista.

Contudo, compete ao Tribunal Superior do Trabalho promover alteração na súmula 337, que só alude à comprovação da divergência jurisprudencial por meio da citação do repositório de jurisprudência, oficial ou credenciado:

$$
\begin{aligned}
& \text { I - Para comprovação da divergência justificadora do recurso, é necessário } \\
& \text { que o recorrente: } \\
& \text { a) Junte certidão ou cópia autenticada do acórdão paradigma ou cite a } \\
& \text { fonte oficial ou repositório autorizado em que foi publicado; e } \\
& \text { b) Transcreva, nas razões recursais, as ementas e/ou trechos dos acórdãos } \\
& \text { trazidos à configuração do dissídio, demonstrando o conflito de teses } \\
& \text { que justifique o conhecimento do recurso, ainda que os acórdãos já se } \\
& \text { encontrem nos autos ou venham a ser juntados com o recurso. } \\
& \text { II - A concessão de registro de publicação como repositório autorizado } \\
& \text { de jurisprudência do TST torna válidas todas as suas edições anteriores. }
\end{aligned}
$$

\subsection{O processo do trabalho e a Lei n. 11.419/2006}

A lei supramencionada não se restringe à promoção de acréscimos e de modificações no Código de Processo Civil, mas disciplina a informatização do processo judicial, estabelecendo claramente a possibilidade da prática, da comunicação e da assinatura eletrônica de quaisquer atos processuais no âmbito civil, penal e trabalhista, bem como nos juizados especiais, em qualquer grau de jurisdição.

Trata-se, portanto, de uma lei geral que consagra a possibilidade do processo que se desenvolverá virtualmente, total ou parcialmente, dispensando a Justiça do Trabalho da mera invocação subsidiária de uma norma destinada ao processo comum. Vê-se claramente que a possibilidade da assinatura por meio eletrônico também será facultada aos órgãos do Poder Judiciário e aos integrantes do Ministério Público, e não somente às partes, peritos e advogados. Contudo, no âmbito trabalhista, a realidade do processo desenvolvido totalmente em ambiente virtual esbarra em dificuldades criadas pela própria Consolidação das Leis do Trabalho (D.L. 5.454, de 01.05.1942. Apesar de várias modificações, ela ainda apresenta peculiaridades em relação à fase de execução, já que a citação para pagar ou garantir a execução deve ser realizada por oficial de justiça, e não por publicação oficial aos 
cuidados do advogado da parte, dificuldade já superada no âmbito civil em face de modificação legislativa (art.475-J do CPC, acrescentado pela Lei 11.232/05), cuja aplicação ao processo do trabalho encontra óbice na ausência de omissão, no diploma consolidado quanto aos procedimentos do início da execução trabalhista (arts. 876 e seguintes da CLT).

\section{Conclusão}

Em síntese, foram apresentadas as mais recentes modificações na legislação que abriga o direito processual comum, algumas aplicáveis em caráter subsidiário ao processo do trabalho ou por expressa determinação (Lei n. 11.419/06), com vistas à maior celeridade e efetividade dos direitos sociais trabalhistas, mormente àqueles reconhecidos pela própria Justiça do Trabalho.

É sabido que no Brasil não existe, propriamente, uma lei processual trabalhista, tampouco um código de processo do Trabalho, e sim a Consolidação das Leis do Trabalho, fruto de decreto-lei do presidente da República (Getúlio Vargas - em 1943). Trata-se de normas de direito material (direito do trabalho) e de direito processual do trabalho, enriquecidos com várias modificações posteriores; incluem-se também algumas leis esparsas, sendo possível, nos casos de omissão legislativa, invocar-se a norma do direito processual comum, por força do próprio art.769 da CLT, desde que não haja incompatibilidade com os princípios que norteiam o processo do trabalho.

Diante das inovações que surgem no âmbito do processo comum e, inclusive, da Lei n. 11.419/06, percebe-se que o momento não é adequado para pensarmos seriamente num código de processo do trabalho. Isto porque existe a necessidade de assimilação das modificações legislativas, mormente aquelas que decorrem das tecnologias da informação, com vistas a identificar as reais necessidades, e até mesmo estabelecer novos contornos do processo do trabalho, considerando a ampliação da competência da Justiça do Trabalho, trazida pela Emenda Constitucional n. 45/2004.

\section{Referências}

ALMEIDA, Cleber Lúcio de. Direito processual do trabalho. Belo Horizonte: Del Rey, 2006.

CASTELLS, Manuel. A galáxia internet: reflexões sobre Internet, negócios e sociedade. Lisboa: Fundação Calouste Gulbenkian, 2004.

FREIRE, Rodrigo da Cunha Lima. Direito fundamental à tutela jurisdicional efetiva na sociedade informacional. In: PAESANI, Liliana Minardi (coord.). O direito na sociedade da informação. São Paulo: Atlas, 2007, p. 305-306. 
194 GARCIA, Gustavo Filipe Barbosa. Terceira fase da reforma do código de processo civil. São Paulo: Método, 2006. v. 2.

FOLHA DE SÃO PAULO, p. B10, 6 set. 2006.

MALLET, Estêvão. O processo do trabalho e as recentes modificações do código de processo civil. Revista LTr 70, São Paulo, n. 6, p. 668-675, jun. 2006.

MARTINS, Adalberto. Justiça do trabalho: uma visão atualizada. Revista do Curso de Direito do Centro Universitário das Faculdades Metropolitanas Unidas, São Paulo, n. 27, ano 19, p. 58-64, 2005.

- A penhora on line no processo do trabalho. In: PAESANI, Liliana Minardi (coord.). O direito na sociedade da informação. São Paulo: Atlas, 2007, p. 317333.

ROMITA, Arion Sayão. Globalização da economia e direito do trabalho. São Paulo: LTr, 1997.

VIEIRA, Antonio Alcio. A súmula n. 337 do TST em face da nova lei n. 11.341/ 2006. LTr Suplemento Trabalhista 114/06, São Paulo, p. 481-485, 2006. 